\section{Plant protection}

SIR,-Your correspondent writing on 'European plant health' (4 January, page 16), draws attention to and criticises certain aspects of the policy of the European and Mediterranean Plant Protection Organisation (EPPO) in listing organisms of plant quarantine significance for the EPPO region and describing them in its data sheets.

It is the function of EPPO to advise member governments on the technical, administrative and legislative measures necessary to prevent the introduction and spread of pests and diseases of plants and plant products. This it does through the agency of its working party on phytosanitary regulations, made up of specialists from nine of the 35 EPPO countries. The working party is, with the full approval of Council, developing procedures in three distinct areas. The first of these is the formulation of lists of non-European (A1) and European (A2) pests, based on extensive research data and the common experience of the plant health services of 35 member countries. The purpose of these lists is to draw the attention of countries to the organisms considered of greatest quarantine importance to the EPPO region so that appropiate precautions are taken in the form of stringent regulations. The second stage is the preparation, for each listed organism, of 'specific quarantine requirements', which EPPO countries are recommended to use as a basis for their phytosanitary regulations. These requirements are addressed specifically to the exporting country and specify conditions which have to be met for the importation of particular plants and plant products, based on the most detailed knowledge available on ease of detection of quarantine organisms in consignments and in the field, on persistence in soil, and so on. It is the formulation and acceptance of these recommendations as a basis for phytosanitary regulations which is the backbone of EPPO's international strategy to ensure that correct and adequate precautions are taken to prevent as far as possible the introduction of new pests without bringing the international exchange of commodities to a standstill. The third element is the preparation of data sheets on the $\mathrm{A} 1$ and $\mathrm{A} 2$ organisms. These sheets are addressed to a wider readership. including on the one hand the plant inspectors of importing and exporting countries and on the other, the general scientific public, which should be better informed on these organisms, many of which are poorly documented at present.

Further details on the activities of EPPO and its working parties will appear in the proceedings of a conference (Plant Health: the Scientific Basis for Administrative Control of Plant Parasites, ed. D. L. Ebbels \& J. E. King) to be published by Blackwells for the Federation of British Plant Pathologists.

At all stages in the formulation of the $\mathrm{A} 1$ and $\mathrm{A} 2$ lists and in the preparation of specific quarantine requirements and data sheets, extensive consultations have been made with research specialists in the EPPO region and throughout the world. The exact status of some potentially dangerous diseases of virus, or virus-like, origin is less certain than that of most of the organisms on the FPPO lists. These uncertainties, which will doubtless be resolved by further research, are clearly stated in the EPPO data sheets and will similarly be reflected in the appropriate specific quarantine requirements. The problem of new strains of quarantine organisms is a very difficult one, which has been thoroughly considered by the working party and can only be resolved at present by applying requirements to all those entities which are indistinguishable in inspection practice from the dangerous ones, or, in extreme cases, by prohibiting the importation of certain plants. It is impossible to foresee the appearance elsewhere in the world of a new aggressive strain of a pathogen already present in a country. Phytosanitary regulations can only be formulated in practice in terms of what is known to exist, not what might exist or appear.. This also applies to pesticide-resistant strains, which may cause considerable trouble when introduced into new areas

We believe that EPPO's phytosanitary strategy, which has been formulated by and has the support of the plant health services of its member countries in consultation with their own specialists, is a sound basis from which to tackle the practical problem of excluding dangerous pests from the region at a time when increasing quantities of exotic products from many parts of the world are being shipped to Europe in fast-moving freight transport. The A1 and A2 lists are under constant review and will be extended as necessary to include other quarantine pests as information on their importance becomes available. If the formulation of the lists and the publication of the data sheets encourages research workers to try to resolve some of the uncertainties about these pests, so much the better. Yours faithfully,

$$
\begin{aligned}
& \text { A. H. STRICKLAND } \\
& \text { G. Mathys } \\
& \text { P. JOURNET } \\
& \text { JAC. FJELIDI)ALFN }
\end{aligned}
$$

EPPO, Paris, France.

\section{Safety in the news}

Sir,-Perhaps some other readers noticed a remarkable coincidence of news items in the 8 March issue of Nature.

First there is the ban, after a ten-year struggle, of the 2.4,5- $\mathrm{T}$ herbicide in the US, because of the presence of dioxin. Then there is the recent release of the file on past nuclear reactor incidents, with the official comment "the absence of more serious effects is largely the result of luck": and the occurrence of accidents with a Rasmussen probability of $10^{-12}$ per year. Also, there is the new official concern in the US with the potential dangers of low levels of radiation previously treated as safe.

Finally, J.D. Watson calls for the deregulation of all DNA research, not merely that on a laboratory scale of the past few vears. but also the industrial-scale research of the future. Yours faithfully. J. R. RAVETZ

University of Leeds. IIK.

\section{Detecting frozen lunar gases}

SIR,- The possibility of sending a lunar satellite into a polar orbit round the moon is being discussed. This will allow the observation of the interiors of craters near the poles, the bottoms of which may never have been reached by the sun since their time of formation. I have suggested earlier (Phys. Bull. 24, 312 and 453; 1973) that in such cold crater bottoms one might find a continuous record of the evolution from the moon's interior of gases such at water. carbon dioxide, and many other materials volatile at lunar day-time temperatures.

In the absence of a significant permanent atmosphere on the moon. individual molecules will travel over a large part of the lunar surface; any which are not swept away by the solar wind or by becoming ionised will eventually find their way to a cold crater and freeze out there. The deposited strata of condensed gases cannot be studied without the landing of appropriate instruments, but the orbiter may make it possible to identify likely places for this.

Over the whole lunar surface, one could expect the top metre of regolith to contain something like fifty million curies of uranium. A large part of the radon-222 derived from the decay of this should be able to escape and with a 31 day half-life has a good chance of reaching the polar region before it decays. An atom of radon would be held in a sunless area and such an area will therefore concentrate the radon itself and its daughters from a much larger area. An observable amount of alpha-activity might therefore be concentrated although good spacial resolution would be needed to observe it Detection would be made easier by the fact that the emission would be effectively from an infinitely thin source since the cold condensed laver would be thick enough to stop all alpha-particles from the underlying long-lived alpha-emitters. It might, however, be worth looking carefully at the energy distribution of the alpha-particles of polonium-210 which. together with its parent lead-210, could be expected to have remained in situ for some decades, during which there might have been some deposition of a detestable thickness of water if there had been any significant emissions of this during the period.

Over most of the lunar surface one would of course expect a thick-source spectrum derived from alpha-emitters still within the regolith with only a small thin-source contribution from the radon in the "gas phase" above the surface. A limit to the relative size of this mav be estimated. The niean thermal velocity of ${ }^{222} \mathrm{Rn}$ at $0^{\circ} \mathrm{C}$ is about $160 \mathrm{~m} \mathrm{~s}^{-1}$.

Leaving the moon's surface normally with this velocity and without collision it would fall back to the surface again in 200 seconds. An average excursion would take about two minutes during which time it would travel horizontally about $20 \mathrm{~km}$. In an average lifetime of five days it could thus make some 3.500 returns to the surface, and a cold crater bottom could expect to collect all the radon from 3.500 times its own area.

This figure must certainly be too high since it assumes an effective albedo of one. or zero resorption by the rest of the surface. This is quite unrealistic. The time of dwell on or in the surface after each return is not known but is clearly not zero. On the other hand, if the satellite could be made to travel well below the top of the radon atmosphere (half height nearly $10 \mathrm{~km}$ ) the background of thin-source particles would be usefully reduced. All in all. it would certainly seem worthwhile to look for possible anomalies of alpha-emission near the poles. Yours faithfully,

J. H. FRFMIIN

Department of Physic:s

University of Birmingham, UK 